\title{
To what extent do smokers plan quit attempts?
}

\section{C Larabie}

Tobacco Control 2005;14:425-428. doi: 10.1136/tc.2005.013615

\begin{abstract}
Aims: Little is known about the extent to which quit attempts are planned ahead or initiated immediately following a sudden decision to quit. This is important because if most smokers quit abruptly, rather than plan ahead, this could impact heavily upon recommendations to health care professionals on the kind of smoking cessation advice they deliver to patients. This paper aims to address this gap in knowledge by examining detailed smoking histories taken from smoking and ex-smoking patients.

Design: Face-to-face in depth semi-structured interviews. Participants: 146 smoking and ex-smoking patients within a family medicine practice were recruited by means of screening 700 consecutive patients (14 years of age and older) and inviting eligible patients to participate. To be eligible, patients had to have smoked a minimum of five cigarettes per day for at least six months in their lives and made at least one serious quit attempt that lasted at least 24 hours. There were no refusals. Ex-smokers ( $n=67$ ) were defined as those who had not smoked for six months. The remainder were classified as smokers $(n=79)$.

Measurements: Participants were asked to describe, in their own words, their most recent quit attempt and whether they had planned the quit attempt in advance, what were the triggers, and how long they abstained. A quit attempt was defined as planned if smokers set a quit date at some future time point. An unplanned quit attempt was defined as a sudden decision not to smoke any more cigarettes including those that might be remaining in the current pack. Information was also collected on methods used to quit and reasons for quitting.

Results: A majority (51.6\%) of quit attempts were reported as being unplanned. The figure was higher for ex-smokers than for smokers $(67.1 \%$ v 36.7\%, $p<0.001)$. Most quit attempts were unaided (64\%) and made for reasons of health (64\%). Conclusions: The finding that so many quit attempts are unprepared suggests that models of smoking cessation should place greater emphasis on the dynamic nature of motivation to quit. This is an area that requires further investigation.
\end{abstract}

$\mathrm{T}$ here is an extensive literature on the processes involved in stopping smoking. It is well understood that stopping smoking is a dynamic process involving repeated attempts to quit followed by relapse. ${ }^{1}$ There are factors that lead an individual to want to stop such as beliefs about the benefits of quitting; ${ }^{2}$ there are factors that trigger a quit attempt such as medical advice or health scares; ; and other factors, such as addiction, influence whether or not that quit attempt is successful. ${ }^{4}$ However, little is known about the extent to which smokers actually plan their quit attempts rather than making a sudden decision not to smoke any more which they then put into immediate effect. According to the theory of planned behaviour, ${ }^{5}$ smokers formulate intentions to stop smoking on the basis of beliefs about the advantages and disadvantages of this, their perception of what others whose views they care about think they should do, and their perception of how likely they are to succeed. These intentions then lead to the behaviour. There is evidence to support the idea that elements of the model predict quitting behaviour, ${ }^{2}{ }^{8}$ but there does not appear to be any information on the timescale between formulating an intention and acting on it. Neither is it known whether unplanned quit attempts are more or less likely to be successful than ones that are planned in advance.

Health care professionals have been directed to help patients quit smoking by following cessation advice guidelines based on the " $4 \mathrm{~A}^{\prime} \mathrm{s}$ " (ask, advise, assist, and arrange $)^{49}$ ). The philosophy underlying much of current practice draws on the stages of change model, which proposes that smokers have to move through a succession of motivational stages to reach the "action" stage at which point they try to stop smoking. ${ }^{10}{ }^{11}$ Not only is it commonly assumed that quit attempts are usually planned in advance, the guidelines specifically recommend this strategy to smokers. Smokers deemed to be in the "preparation" stage are advised to plan ahead for a quit day. ${ }^{10}$ Thus, rather than support unplanned or abrupt ("cold turkey") quitting, the present delivery of smoking cessation advice is designed to move smokers through the supposed stages. By matching interventions to the patient's stage it is claimed that it is possible to plant the seed for possible quitting at some time in the future. However, there does not appear to be evidence in the literature that this does in fact occur. ${ }^{12}$ This model has been criticised on numerous grounds, ${ }^{12-16}$ but one of the major tenets of the model that has not been thoroughly explored is the extent to which smokers do actually prepare their quit attempts.

An alternate theory that may serve as a starting point for understanding quit attempts is "choice theory", which has been applied to alcohol dependence but has potential applicability to any health related behaviour. ${ }^{17}$ This theory argues that it is useful to focus on the fact that individuals make and implement momentary choices both with regard to ceasing an unhealthy behaviour and relapsing, and this reflects strong appetites and highly dynamic conflicting motives. According to choice theory, people dependent upon alcohol are "dynamically inconsistent planners". If dependent smokers are similar to people dependent upon alcohol they may also give in to temptation and abandon their prior good intentions to quit smoking. The dynamic nature of motivation in relation to the current situation and preexisting plans has been highlighted further in an attempt at an integrative theory of motivation. ${ }^{18}$ Advising smokers to plan ahead to quit may in some cases be counterproductive by pushing the decision to quit smoking further into the future, which might be dangerous territory for the ambivalent would-be quitter. In addition, determining readiness to quit is highly dependent upon a smoker's estimate of when they will quit smoking. How meaningful is it to ask someone who fluctuates in his or her orientation toward the future ${ }^{17}$ 
whether or not he or she intends to quit smoking in 30 days or six months? This study aimed to address this gap in the literature by interviewing smokers and ex-smokers about their quitting experiences and, in particular, inquiring whether quit attempts were planned ahead or not.

\section{METHODS}

\section{Subjects and setting}

Consecutive patients (14 years of age and older) who appeared at the family doctor's office for scheduled medical appointments were asked at the conclusion of the consultation a number of screening questions pertaining to their smoking history by the physician. The age of 14 years was arbitrarily selected because this is a common age for many smokers to report onset of dependent smoking. Patients were eligible to take part if they had smoked five or more cigarettes a day for at least six months and had made at least one serious attempt to stop smoking that had lasted a minimum of 24 hours. Seventeen patients who had never attempted to quit smoking (never quitters) were excluded from the study. Two pipe smokers and three smokers who smoked less than five cigarettes per day were also excluded from the study. Patients who met the screening criteria were then asked by the physician for written consent to participate in the study. A total of 700 consecutive patients were approached and 146 were eligible and agreed to be interviewed. There were no refusals. Ex-smokers were defined as those who had not smoked for at least six months. There were 67 ex-smokers and 79 smokers. Approval for the study was secured from Queen's University ethics review board.

\section{Interviews}

At the conclusion of the medical appointment, eligible patients who consented to participate in the study remained in the doctor's office to provide a personal smoking history. The author conducted all 146 interviews. By way of introduction, participants were asked questions pertaining to smoking history, including age when they first began to smoke, number of cigarettes smoked per day, and number of years they had been a smoker. Afterwards, participants were asked about the number of previous quit attempts. For the most recent quit attempt they were asked about reasons for attempting to quit, methods used to quit smoking, what triggered the quit attempt, whether they quit abruptly ("cold turkey") or gradually, whether they planned the quit attempt in advance, and how long they had abstained. A formal interview guide was not used. The latter questions were open ended and interviews, lasting an average of 20-25 minutes, continued until the person ran out of new things to say. Subjects were encouraged to say what they really felt and that there were no "right or wrong answers". Subjects gave their own reasons for quitting, whether they quit abruptly, etc, in their own words. Responses were recorded "verbatim" in writing by the physician, in the same manner as taking a medical history from a patient.

The key measure of interest was whether or not quit attempts were "planned" or "unplanned". A quit attempt was defined as planned if smokers undertook any activity that pre-dated the quit attempt and was designed to help that attempt to succeed. An unplanned quit attempt was defined as a sudden decision not to smoke any more cigarettes, including those that might be remaining in the current pack. Responses were also categorised as to reasons for stopping (health, cost, disgust with smoking, other) and method of stopping (no aid, nicotine replacement, bupropion, tapering). The physician was the sole analyst of the data. The interview process took a year to complete. Participants did not receive any payment for their participation in the study.

\section{RESULTS}

Table 1 shows the demographics and smoking history of smokers and ex-smokers.

The majority of ex-smokers reported that they required three or more attempts before achieving long term abstinence from smoking (52\%). Most current smokers also reported that they had made three or more quit attempts $(51 \%)$. Table 1 shows that the majority of quit attempts had been unplanned (51\%); this figure was higher for ex-smokers than

\begin{tabular}{|c|c|c|c|}
\hline & $\begin{array}{l}\text { Smokers } \\
(\mathrm{n}=79)\end{array}$ & $\begin{array}{l}\text { Ex-smokers } \\
(\mathrm{n}=67)\end{array}$ & $\begin{array}{l}\text { Total } \\
(n=146)\end{array}$ \\
\hline Mean (range) age (years) & $40(16-78)$ & $52(30-84)$ & $45(16-84)$ \\
\hline Number (\%) female & $62(78 \%)$ & $45(67 \%)$ & $107(73 \%)$ \\
\hline Mean (range) age started smoking regularly & $17(9-38)$ & $18(10-33)$ & $17(9-38)$ \\
\hline Mean (range) number of cigs per day & $16(5-37)$ & $21(5-68)$ & $18(5-68)$ \\
\hline Mean (range) number of years smoked & $23(2-60)$ & $21(1-49)$ & $22(1-60)$ \\
\hline $\begin{array}{l}\text { Mean length of time (range) as an ex-smoker } \\
\text { ( } 6 \text { months minimum) }\end{array}$ & - & $\begin{array}{l}13.3 \text { years } \\
(10 \mathrm{~m}-40 \mathrm{y})\end{array}$ & \\
\hline \multicolumn{4}{|l|}{ Number of quit attempts } \\
\hline One & $15(19 \%)$ & $16(24 \%)$ & $31(21 \%)$ \\
\hline Two & $24(30 \%)$ & $16(24 \%)$ & $40(27 \%)$ \\
\hline Three & $17(22 \%)$ & $13(19 \%)$ & $30(21 \%)$ \\
\hline More than three & $23(29 \%)$ & $22(33 \%)$ & $45(31 \%)$ \\
\hline \multicolumn{4}{|l|}{ Quitting methods } \\
\hline No aid & $40(51 \%)$ & $53(79 \%)^{*}$ & $93(64 \%)$ \\
\hline Bupropion & $12(15 \%)$ & $7(10.5 \%)$ & $19(13 \%)$ \\
\hline Patch & $13(16 \%)$ & $2(3 \%)$ & $15(10 \%)$ \\
\hline Nicotine gum & $5(7 \%)$ & $1(1.5 \%)$ & $6(4 \%)$ \\
\hline Tapering & $9(11 \%)$ & $3(4.5 \%)$ & $12(8 \%)$ \\
\hline Hypnosis & - & $1(1.5 \%)$ & $1(1 \%)$ \\
\hline \multicolumn{4}{|l|}{ Unplanned or planned quitting } \\
\hline Unplanned & $29(37 \%)$ & $45(67 \%)^{*}$ & $74(51 \%)$ \\
\hline Planned & $50(63 \%)$ & $22(33 \%)$ & $72(49 \%)$ \\
\hline \multicolumn{4}{|l|}{ Reasons for quitting } \\
\hline Health & $50(63 \%)$ & $43(64 \%)$ & $93(64 \%)$ \\
\hline Cost & $4(5 \%)$ & $1(2 \%)$ & $5(3 \%)$ \\
\hline Disgust with smoking & $4(5 \%)$ & $6(9 \%)$ & $10(7 \%)$ \\
\hline Others & $21(27 \%)$ & $17(25 \%)$ & $38(26 \%)$ \\
\hline
\end{tabular}


smokers $\left(67 \%\right.$ and $37 \%$, respectively, $\left.\chi^{2}=13.5, \mathrm{p}<0.001\right)$. Sixty four per cent of all quit attempts did not involve any form of assistance. Once again, this figure was higher for exsmokers than smokers $(79 \%$ and $51 \%$, respectively, $\left.\chi^{2}=12.7, \mathrm{p}<0.001\right)$. Examples of responses made by patients are given in the appendix (to view the appendix visit the Tobacco Control website-http://www.tobaccocontrol.com).

The three most commonly reported types of planning for quit attempts were: planning ahead to quit on a specified or significant date (for example birthday, New Year's Eve); making arrangements to obtain nicotine replacement medication (nicotine gum, nicotine patch), or bupropion, before quitting; and deferring quitting until they had finished smoking all the cigarettes remaining in their current pack. The reasons for quitting followed the kind of patterns seen in other studies, with health as the main factor (table 2).

\section{DISCUSSION}

The present study appears to be the first to examine how often quit attempts are made abruptly once an intention has been formulated. It found that a majority were unplanned. Successful quit attempts, particularly among the ex-smokers, were more likely to be unplanned than unsuccessful ones. As with other studies, ex-smokers reported multiple quit attempts before attaining lasting abstinence from nicotine. ${ }^{1}$

The results indicate that any comprehensive description of the quitting process must allow for the highly dynamic nature of motivation, and explicitly address the timescale

Table 2 Examples of reasons for successfully quitting smoking without planning

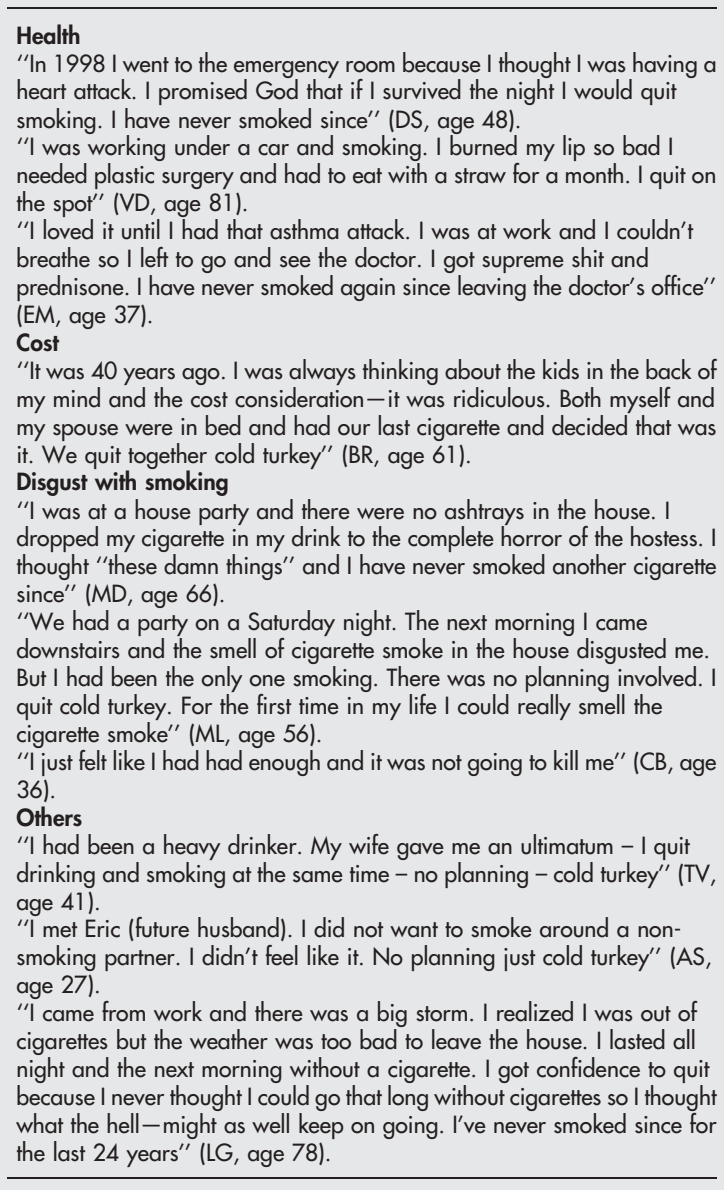

\section{What this paper adds}

Health care professionals have been directed to help patients quit smoking by following cessation guidelines based on the stages of change " $4 \mathrm{~A}^{\prime} \mathrm{s}$ " (ask, advise, assist, and arrange). Not only is it commonly assumed that quit attempts are usually planned in advance, the guidelines specifically recommend this strategy to smokers. However, the extent to which smokers actually prepare their quit attempts has not been explored. This question is important because, if smokers tend to quit spontaneously, the current guidelines may be hindering, rather than assisting successful smoking cessation.

This study found that a majority of successful quit attempts were unplanned, a finding which raises the possibility that implementing a decision to quit immediately may improve its likelihood of success. This needs to be explored as a matter of urgency as it has important implications for recommendations to health professionals on the kind of advice they deliver.

between deciding to change and implementing that decision. Many smokers try to quit abruptly, some for seemingly trivial reasons (for example, thunderstorm preventing the purchase of a pack of cigarettes) and remain abstinent for years. The findings appear to contradict a basic assumption of the transtheoretical model of behaviour change which posits discrete stages in the process of quitting. Of course proponents of that theory can always argue that the stages can on occasion be completed within a very short space of time, but this would then make any statement about stages all but meaningless. The data are more in accord with a concept of motivation based on "chaos theory" which recognises that behaviour patterns are more like "weather systems" than "hydraulic systems" - it is predictable to an extent but there is a fundamental instability. ${ }^{18}$

The data also tie in quite well with choice theory. Quitting opportunities or "moments" can appear anywhere, at any time, in any shape or form (see examples in appendix). Choosing to quit abruptly at the right quitting moment can clearly lead on occasion to lasting abstinence. It is not known what key interaction of environment or people can tip the balance for a person to quit smoking. Therefore, it makes sense to encourage smokers to both recognise and act upon "abrupt" opportunities-for example, "If you run out of cigarettes during a thunderstorm, try to quit. Don't plan quit dates; look for quit opportunities." Perhaps health care practitioners should encourage as many quit attempts as possible (keeping in mind that the only good predictor of success has been connected to the number of prior quit attempts ${ }^{19}$ ) in the hope that each attempt is another "roll of the dice".

The findings that successful quit attempts were more likely to be unplanned is surprising but obviously could arise from recall bias. It could also be that smokers that plan quit attempts ahead are those that find it more difficult to quit because they are more dependent. However, the finding raises the possibility that implementing a decision to quit immediately, once that decision is made, may in fact improve its likelihood of success. This needs to be explored as a matter of urgency because if making a sudden unplanned quit attempt is at least as effective-other things being equal-as making one that is planned, it has important implications for recommendations to health professionals on the kind of advice they deliver.

The present study is clearly limited in being drawn from a single general practice population over a limited time period, 
and relying on retrospective reports. Despite the imperfections, this study opens up an area of investigation that has so far been lacking which might provide new insights into the quitting process.

\section{ACKNOWLEDGEMENTS}

I wish to sincerely thank Dr Roy M Pritchard, Dr Marshall Godwin, and Professor Robert West for their invaluable advice and support throughout the writing of this paper. I am grateful to Dr Edith D Balbach for the idea that smokers ought to recognise and act upon quitting opportunities, rather than plan quit dates.

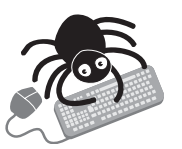

To view appendix visit the Tobacco Control websitehttp://www.tobaccocontrol.com

Competing interests: none declared

Correspondence to: Lynn C Larabie, 797 Princess Street, Princess Anne Building, Suite 411, Kingston, Ontario, Canada, K7L 1G1; larabie@ kingston.net

Received 18 July 2005

Accepted 22 September 2005

\section{REFERENCES}

1 Cohen S, Lichtenstein E, et al. Debunking myths about self-quitting. Evidence from 10 prospective studies of persons who attempt to quit smoking by themselves. Am Psychol 1989:44:1355-65.

2 West R, McEwen A, Bolling K, et al. Smoking cessation and smoking patterns in the general population: a 1-year follow-up. Addiction 2001;96:891-902.
3 Lader D, Goddard E. Smoking related attitudes and behaviour, 2003. London: Office of National Statistics, 2004.

4 Royal College of Physicians. Nicotine addiction in Britain. London: RCP, 2000.

5 Hu SC, Lanese RR. The applicability of the theory of planned behavior to the intention to quit smoking across workplaces in southern Taiwan. Addict Behav 1998;23:225-37

6 Norman P, Conner M, Bell R. The theory of planned behavior and smoking cessation. Health Psychol 1999;18:89-94.

7 Riedel B, Robinson L, Klesges RC, et al. What motivates adolescent smokers to make a quit attempt? Drug Alcohol Depend 2002;68:167.

8 Rose JS, Chassin L, Presson CC, et al. Prospective predictors of quit attempts and smoking cessation in young adults. Quitting motives and barriers among older smokers. The 1986 Adult Use of Tobacco Survey revisited. Health Psychol 1996;15:261-8.

9 Society for Clinical Preventive Health Care. British Columbia doctors stopsmoking programme (BCDSSP). Canada: Society for Clinical Preventive Health Care, 2002.

10 Zimmerman G, Olsen C, Bosworth M. A "stages of change" approach to helping patients change behaviour. Am Family Physician 2000;6:1409-22.

11 Prochaska JO, Velicer WF. The transtheoretical model of health behavior change. Am J Health Promot 1997;12:38-48.

12 Rollnick S, Butler CC, Stott N. Helping smokers make decisions: the enhancement of brief intervention for general medical practice. Patient Educ Couns 1997;31:191-203.

13 Abrams DB, Herzog TA, Emmons KM, et al. Stages of change versus addiction: a replication and extension. Nicotine Tob Res 2000;2:223-9.

14 Etter JF, Sutton S. Assessing 'stage of change' in current and former smokers Trying to stop smoking: effects of perceived addiction, attributions for failure, and expectancy of success. Addiction 2002;97:1171-82.

15 Sutton S. Back to the drawing board? A review of applications of the transtheoretical model to substance use. Addiction 2001:96:175-86.

16 West R. Time for a change: putting the transtheoretical (stages of change) model to rest. Addiction 2005;100:1039-9.

17 Skog OJ. Addicts' choice. Addiction 2000;95:1309-14.

18 West R. Theory of addiction. Oxford: Blackwells, 2005.

19 Prochaska JO, Diclemente CC, et al. In search of how people change: applications to addictive behaviours. American Psychologist 1992;47:1 102-14.

\section{bmjupdates+}

bmiupdates+ is a unique and free alerting service, designed to keep you up to date with the medical literature that is truly important to your practice.

bmjupdates+ will alert you to important new research and will provide you with the best new evidence concerning important advances in health care, tailored to your medical interests and time demands.

Where does the information come from?

bmiupdates+ applies an expert critical appraisal filter to over 100 top medical journals A panel of over 2000 physicians find the few 'must read' studies for each area of clinical interest

Sign up to receive your tailored email alerts, searching access and more...

www.bmjupdates.com 